\title{
Validity of Current Somatoform Disorder Diagnoses: Perspectives for Classification in DSM-V and ICD-11
}

\author{
Bernd Löwe ${ }^{\mathrm{a}}$ Christoph Mundt ${ }^{\mathrm{b}}$ Wolfgang Herzog ${ }^{\mathrm{a}}$ Romuald Brunner ${ }^{\mathrm{c}}$ \\ Matthias Backenstrass $^{b}$ Klaus Kronmüller ${ }^{b}$ Peter Henningsen ${ }^{d}$ \\ Departments of a Psychosomatic and General Internal Medicine, ${ }^{b}$ Psychiatry and ${ }^{c} C h i l d$ and Adolescent Psychiatry, \\ Center of Psychosocial Medicine, University of Heidelberg, Heidelberg, and ${ }^{\mathrm{d}}$ Department of Psychosomatic \\ Medicine and Psychotherapy, Technical University of Munich, Munich, Germany
}

\section{Key Words}

Somatoform disorders, diagnosis, validity $\cdot$ Reproducibility of results $\cdot$ Diagnostic and Statistical Manual of Mental Disorders, classification $\cdot$ International Classification of Diseases $\cdot$ Literature review

\begin{abstract}
Background: The impending revisions of DSM-IV and ICD-10 provide an excellent opportunity to improve the diagnostic accuracy of the current somatoform disorder classification. To prepare for these revisions, this study systematically investigates the validity of the current classification of somatoform disorders. Methods: We searched Medline, Psycinfo and reference lists to investigate convergent, divergent, criterion and predictive validity of the current somatoform disorder classification. Results: Substantial associations of somatoform disorders with functional impairment and elevated health care costs give evidence for the clinical and societal importance of somatoform disorders and for the convergent validity of the current operationalization. The specificity of the current somatoform disorder classification, i.e. their divergent validity, is demonstrated by the fact that functional somatic syndromes and their consequences are only partially explained by association with anxiety and depression. However, the imprecision of the diagnostic criteria,
\end{abstract}

which are not based on positive criteria but on the exclusion of organic disease, largely limits the criterion validity of the current classification systems. Finally, studies investigating the predictive potential of somatoform disorders are lacking, and to date predictive validity has to be considered as low. Conclusions: The insufficient criterion and predictive validity of the present somatoform classification underlines the need to revise the diagnostic criteria. However, an abolishment of the whole category of somatoform disorders would ignore the substantial convergent and divergent validity of the current classification and would exclude patients with somatoform symptoms from the current health care system. A careful revision of the current somatoform disorder diagnoses, based on positive criteria of psychological, biological and social features, has the potential to substantially improve the reproducibility and clinical utility of the existing classification system.

Copyright $\odot 2007$ S. Karger AG, Basel

\section{Introduction}

The impending revisions of DSM-IV [1] and ICD-10 [2] provide an excellent opportunity to improve the current diagnostic categories. Among the most critically discussed diagnostic categories is the somatoform disorder

\section{KARGER}

Fax +4161306 1234 E-Mail karger@karger.ch www.karger.com
(C) 2007 S. Karger AG, Basel

0254-4962/08/0411-0004\$24.50/0

Accessible online at:

www.karger.com/psp
Bernd Löwe, MD, PhD, Department of Psychosomatic and General Internal Medicine Center of Psychosocial Medicine, University of Heidelberg, Medical Hospital, INF 410 DE-69120 Heidelberg (Germany)

Tel. +49 6221568 999, Fax +496221565749

E-Mail bernd.loewe@med.uni-heidelberg.de 
section. The category of somatoform disorders was introduced into DSM-III [3] in 1980 to summarize conditions that are characterized by medically unexplained symptoms and substantial functional impairment. Since then, several revised diagnostic algorithms have been proposed, such as 'multisomatoform disorder' [4], 'abridged somatization disorder' [5] or 'polysymptomatic somatoform disorder' [6]. However, despite the unquestioned clinical and societal importance of persistent medically unexplained symptoms [7], so far, no consensus regarding the diagnostic definition has been reached. While some researchers go so far as to require the abolition of the whole diagnostic category $[8,9]$, others favor a thoughtful revision of the existing somatoform disorder section [10-16].

The investigation of the validity of the current somatoform disorder classification is a precondition to improve diagnostic classification in DSM-V and ICD-11. Although several papers have focused on specific diagnostic issues of somatoform disorders $[8,17-21]$, to date no systematic report on the validity of somatoform disorders is available. Systematic reviews on the validity of diagnostic categories require formal criteria to establish the validity of psychiatric diagnosis. In order to systematically investigate whether the current diagnostic criteria of somatoform disorders are valid, we applied the psychological concepts of validity [22] to the diagnostic category of somatoform disorders. In detail, we investigated the different subtypes of validity, i.e. convergent, divergent, criterion and predictive validity. From the results of these investigations, we derive suggestions for the future classification of somatoform disorders.

\section{Methods}

To investigate the different validity subtypes of somatoform disorder, we searched Medline, Psycinfo and reference lists from relevant publications. In addition, the discussion of relevant topics on somatoform disorders at 3 current research conferences (Conceptual Issues in Somatoform and Similar Disorders, London, 2005, and Oxford, 2006; Functional and Somatoform Disorders Conference, Heidelberg, 2006) influenced the current report. The 4 most important subtypes of validity were specifically investigated for somatoform disorders. To better illustrate the significance of the different subtypes of validity for somatoform disorders, each subtype is characterized by a question leading investigation and report.

Convergent validity is a subtype of construct validity and describes the degree to which the operationalization converges on other operationalizations that it theoretically should be related to [23]; e.g. significant associations of somatoform disorders with indicators of impaired health would support convergent validity of the somatoform disorder category. Thus, the investigation of convergent validity of somatoform disorders can be characterized by the following question: 'Are we talking about something of importance?'

Divergent validity describes the specificity of the relevant operationalization, i.e. the extent to which it is different from other operationalizations that it should not be similar to. Divergent validity is another subtype of construct validity. If both convergent and divergent validity have been demonstrated for a specific operationalization, there is strong evidence for its construct validity. With respect to somatoform disorders, divergent validity can be summarized as follows: 'Is it something specific we are talking about?'

Criterion validity is usually regarded as the most important aspect of validity. It describes the performance of the operationalization against a criterion standard [24]. Of course, the investigation of criterion validity requires the presence of clear criteria defining both operationalization and criterion standard. Thus, the first question regarding criterion validity of somatoform disorders must be: 'Do we know what exactly we are talking about?'

Predictive validity describes the ability of the operationalization to predict the future occurrence of events it should be able to predict [24]. For somatoform disorders, this subtype of validity implies a valid conceptual model as a basis for hypotheses regarding future events. To investigate this subtype of validity in somatoform disorders, the leading question is: 'Do we have an accepted conceptual model?

\section{Results}

\section{Are We Talking about Something of Importance (Convergent Validity)?}

Several studies investigated the association of somatoform disorders with functional impairment and health care costs [7, 25-28]. Spitzer et al. [25] reported that primary care patients with somatoform disorders had 4 times as many disability days as patients without that disorder. In another study, somatizing patients, when compared with nonsomatizing ones, had more primary care and specialty visits, more hospital admissions, as well as higher in- and outpatient costs [7]. The decrease in employment rate over the lifespan was found to be significantly larger among patients with somatoform disorders compared to patients with no or other mental disorders [26]. Given that a high prevalence rate of $16.1 \%$ of somatoform disorders was found in primary care [20], these results and those from other studies $[27,28]$ underline that the somatoform disorder category is associated with substantial functional impairment and elevated health care costs. This association is not only an indicator for the significant clinical and societal importance of somatoform disorders but also for the convergent validity of the current operationalization of somatoform disorders. 


\section{Is It Something Specific We Are Talking about}

(Divergent Validity)?

A crucial issue for divergent validity of psychiatric diagnoses is whether the psychiatric syndromes are separated from one another or whether they are merely arbitrary loci in a multidimensional space in which variation in symptoms is more or less continuous [29-31]. Among the functional somatic syndromes, 3 are mentioned more regularly than others: irritable bowel syndrome, chronic fatigue syndrome and fibromyalgia, probably because of the existence of well-defined and/or popular research diagnostic criteria [32]. Empirically, many patients fulfill criteria for more than 1 functional somatic syndrome and unexplained clinical conditions show substantial overlap with other unexplained clinical conditions $[33,34]$. The extent of this empirical overlap between single functional somatic syndromes reaches from around $10 \%$ in the general population to over $50 \%$ in clinic populations [32]. Similarly, substantial overlap was described for somatoform disorders, anxiety and depression. Within the somatoform disorder category, overlap with anxiety and/or depressive disorders was described in $26-59 \%$ of cases [7, 20 , 35]. However, as evidenced by a recent meta-analytic review, functional somatic syndromes are not entirely explained by association with anxiety and depression [11] and costs have been shown to be elevated in somatizing patients without comorbid anxiety or depression [7]. Thus, somatoform disorders appear to have an important specific effect on disability and health care costs, independently of other mental or physical conditions. Therefore, the criteria for divergent validity of somatoform disorders are at least partially met.

\section{Do We Know What Exactly We Are Talking about} (Criterion Validity)?

For patients presenting with persistent medically unexplained symptoms, the clinician has a wide range of diagnostic opportunities.

1 Given that diagnostic criteria are met, the clinician could either diagnose a somatoform (DSM-IV: axis I) or a functional disorder (DSM-IV: axis III). However, in clinical practice, whether a functional or a somatoform disorder is diagnosed essentially depends on the treatment setting - while functional disorders are the preferred diagnoses in medical settings, somatoform disorders tend to be the favored ones in psychosocial settings.

2 The clinician could either use DSM-IV or ICD-10 diagnostic criteria. For the somatoform disorder section, DSM-IV and ICD-10 differ largely with respect to both diagnostic categories and diagnostic criteria $[1,2]$. Whether DSM-IV or ICD-10 is used in clinical practice is usually determined by the country and the health care system the clinician is working in.

3 Finally, the clinician could use original or modified criteria for somatoform disorders. The modified criteria for 'multisomatoform disorder' [4], 'abridged somatization disorder' [5] or 'polysymptomatic somatoform disorder' [6] were adopted for several research projects; but to date they are usually not accepted for clinical care or financial purposes.

The many diagnostic opportunities indicate the insufficient precision of the current diagnostic criteria for somatoform disorders. As a matter of fact, the existing diagnostic criteria of both DSM-IV and ICD-10 are not supported by substantial empirical evidence $[8,10]$. In addition, they are not based on positive criteria but on the exclusion of organic disease $[1,2]$. Finally, the biopsychosocial multidimensionality of somatoform disorders is not reflected by the current classification systems $[1,2]$. Especially psychological and interpersonal factors known to be associated with somatoform disorders are neglected by the current classification systems. These factors include excessive health care use, selective attention to physical symptoms, cognitive misinterpretation ('catastrophizing') of harmless physical symptoms, body scanning and checking, decreased activity and avoidance and an impaired doctor-patient communication $[6,19,36-$ 38]. Altogether, these investigations suggest that we do not really know what exactly is described by the category 'somatoform disorders' and that criterion validity is insufficient.

\section{Do We Have an Accepted Conceptual Model}

(Predictive Validity)?

From the end of the 19th century on, theoretical models of medically unexplained symptoms were developed. These models, largely based on concepts of dissociation [39], conversion [40] and somatization [41-43], substantially influenced treatment and helped understand the development of physical symptoms in many patients. However, none of these models was able to provide a comprehensive and verifiable explanation for the development of somatoform symptoms [44, 45]. Recently, psychobiological models have increased our knowledge about somatoform disorders [46], but so far, they do not reflect the complexity of somatoform disorders adequately. The most promising conceptual models of somatoform disorders are multifactorial and include psychological, biological and interpersonal aspects [44, 47]. Al- 
though these models represent the great progress that has been made in the conceptualization of somatoform symptoms during the past 20 years, it remains unclear whether these models are able to prospectively predict the development of somatoform disorders in individuals. At this point, the predictive potential of the existing conceptual models remains to be tested, and therefore predictive validity has to be considered as low.

\section{Discussion}

Our investigations suggest that the conditions described by the current somatoform disorder diagnostic criteria are of high clinical and societal importance and include specific aspects that cannot be fully explained by other disorders. However, due to the weakness of the current diagnostic criteria, the accuracy of the diagnosis is poor; in addition, conceptual models with proven predictive ability are missing. Thus, despite satisfactory convergent and divergent validity; criterion and predictive validity must be regarded as unsatisfactory. Given that criterion validity is generally considered the strongest subtype of validity, its insufficiency must be regarded as a particularly serious limitation to the general validity of somatoform disorders.

What consequences have to be drawn from these results with respect to the future classification of somatoform disorders in DSM-V and ICD-11? Firstly, given the impaired accuracy of the current diagnostic criteria - i.e. low criterion validity - the diagnostic criteria cannot be adopted for the revised classification systems as they are. In fact, the need to revise the diagnostic criteria of somatoform disorders is undisputed among the vast majority of researchers $[12,16,21,37,48-51]$. Secondly, a complete abolition of the somatoform disorder category $[8,9]$ does not appear appropriate, due to the specificity and the personal, clinical and societal importance of the disorder. Patients with somatoform symptoms represent a major group of patients with abnormal health care use and increased disability in primary care $[7,16,25]$. An abolishment of the somatoform disorder category without a substitute would mean to abandon this large patient group and to exclude them from appropriate treatment. In addition, the introduction of somatoform disorders in DSM-III has stimulated research and improved treatment [13]. Consequently, abolishment would mean stepping backwards [14]. Thirdly, given that not the importance of somatoform disorders but the accuracy of its diagnostic criteria is questionable, a thoughtful revision is clearly the preferable consequence of our analyses of the general validity of somatoform disorder classification in DSM-IV and ICD-10.

Recommendations for future classification of somatoform disorders can also be derived from our analyses. Considering the many diagnostic opportunities for unexplained physical symptoms, an important task would be to reunite (a) the diagnostic criteria of DSM-V and ICD-11, (b) the criteria for functional and somatoform disorders, and (c) the original and the modified criteria of somatoform disorders. This reunification would prevent patients from falling victim to a dichotomous health care system with the psychosocial specialties on the one side and medical specialties on the other. The solution to this problem would require more radical approaches, e.g. to host somatoform/functional disorders with identical diagnostic criteria on both medical and psychiatric axes of the classification systems, to change the axes radically [52], or to conceptualize somatoform disorder as an 'interface disorder'. In addition, the future diagnostic criteria should better reflect the obvious psychobiosocial multidimensionality of somatoform disorders. Therefore, the diagnosis should not only be based on the exclusion of organic disease but on positive criteria of psychosocial features, such as (a) selective attention to bodily signals ('scanning and checking'), (b) dysfunctional cognitions (e.g. catastrophizing interpretations of bodily signals), (c) persistent attribution of symptoms to undiagnosed physical conditions, (d) excessive health care use, (e) decreased activity and avoidance, and (f) functional impairment due to somatoform symptoms. Given that the vast majority of patients with unexplained physical symptoms present in primary care, it is recommended that future classification systems incorporate diagnostic criteria that are relevant to and practical for use in primary care $[10,15]$. Naturally, persistent physical symptoms without known organic origin will continue to be a prominent feature of somatoform disorders.

Our conceptual article regarding the validity of somatoform disorders has the potential limitation that a systematic investigation of the reliability of the disorders was not included. Given that reliability is considered a precondition for the validity of a concept, our investigation of validity in fact partly includes the investigation of reliability. Of note, a prospective study has demonstrated a low stability of somatoform symptoms over time [53]. This result might at least to some extent explain the difficulty of developing conceptual models that are able to predict the development of somatoform symptoms in individuals. Similarly, we did not include the investigation 
of clinical utility [29] of the somatoform disorder category in this paper because this question was already tackled by earlier treatment studies and reviews. In brief, the category of somatoform disorders appears therapeutically useful because psychological therapies [32, 54, 55] and antidepressant medication $[11,32,56-58]$ were shown to be efficacious for many patients with somatization.

Further research is needed to better describe epidemiological, genetic, physical, psychological, behavioral and interpersonal correlates of somatoform symptoms. This research could help identify and validate 'candidate' diagnostic features for the classification of somatoform disorders in DSM-V and ICD-11. For instance, case control studies, comparing cases with somatoform/functional symptoms and noncases regarding illness behavior, health care utilization, perceptual aspects, cognitive styles, childhood experiences, attachment styles, (sub)cortical patterns and physiological arousal, would tremendously help designate future diagnostic criteria for somatoform disorders. Additionally, prospective studies are necessary to better investigate the duration, course, stability and frequency of physical, psychological and interpersonal patterns associated with somatization [37]. Finally, cross-sectional studies, investigating the unique contribution of somatization, depression and anxiety to disability days, health care use and health related quality of life could help establish somatoform disorders as a separate diagnostic entity. Altogether, a thoughtful revision of the current classification of somatoform disorders appears timely and useful for patients, clinicians and researchers.

\section{References}

1 American Psychiatric Association: Diagnostic and Statistical Manual of Mental Disorders, ed 4, rev (DSM-IV-TR). Washington, American Psychiatric Association, 2000.

2 World Health Organization: The ICD-10 Classification of Mental and Behavioural Disorders. Clinical Descriptions and Diagnostic Guidelines. Geneva, World Health Organization, 1992.

3 American Psychiatric Association: Diagnostic and Statistical Manual of Mental Disorders, ed 3 (DSM-III). Washington, American Psychiatric Association, 1980.

4 Kroenke K, Spitzer RL, deGruy FV 3rd, Hahn SR, Linzer M, Williams JB, Brody D, Davies M: Multisomatoform disorder: an alternative to undifferentiated somatoform disorder for the somatizing patient in primary care. Arch Gen Psychiatry 1997;54:352358 .

$\checkmark 5$ Escobar JI, Manu P, Matthews D, Lane T, Swartz M, Canino G: Medically unexplained physical symptoms, somatization disorder and abridged somatization: studies with the Diagnostic Interview Schedule. Psychiatr Dev 1989;7:235-245.

-6 Rief W, Hiller W: Toward empirically based criteria for the classification of somatoform disorders. J Psychosom Res 1999;46:507518.

7 Barsky AJ, Orav EJ, Bates DW: Somatization increases medical utilization and costs independent of psychiatric and medical comorbidity. Arch Gen Psychiatry 2005;62:903910.

-8 Mayou R, Kirmayer LJ, Simon G, Kroenke K, Sharpe M: Somatoform disorders: time for a new approach in DSM-V. Am J Psychiatry 2005;162:847-855. $\checkmark 9$ Sykes R: Somatoform disorders in DSM-IV: mental or physical disorders? J Psychosom Res 2006;60:341-344.

10 Fink P, Rosendal M, Olesen F: Classification of somatization and functional somatic symptoms in primary care. Aust NZ J Psychiatry 2005;39:772-781.

11 Henningsen P, Zimmermann T, Sattel H: Medically unexplained physical symptoms, anxiety, and depression: a meta-analytic review. Psychosom Med 2003;65:528-533.

12 Levenson JL: A rose by any other name is still a rose. J Psychosom Res 2006;60:325-326.

13 Hiller W: Don't change a winning horse. J Psychosom Res 2006;60:345-347.

14 Hiller W, Rief W: Why DSM-III was right to introduce the concept of somatoform disorders. Psychosomatics 2005;46:105-108.

15 Rosendal M, Fink P, Bro F, Olesen F: Somatization, heartsink patients, or functional somatic symptoms? Towards a clinical useful classification in primary health care. Scand J Prim Health Care 2005;23:3-10.

16 Rief W, Henningsen P, Hiller W: Classification of somatoform disorders. Am J Psychiatry 2006;163:746-747.

17 Sharpe M, Mayou R: Somatoform disorders: a help or hindrance to good patient care? $\mathrm{Br}$ J Psychiatry 2004;184:465-467.

18 Creed F, Barsky A: A systematic review of the epidemiology of somatisation disorder and hypochondriasis. J Psychosom Res 2004;56: 391-408.

19 Rief W, Nanke A, Emmerich J, Bender A, Zech T: Causal illness attributions in somatoform disorders: associations with comorbidity and illness behavior. J Psychosom Res 2004;57:367-371.
20 De Waal MW, Arnold IA, Eekhof JA, Van Hemert AM: Somatoform disorders in general practice: prevalence, functional impairment and comorbidity with anxiety and depressive disorders. Br J Psychiatry 2004;184: $470-476$

21 Starcevic V: Somatoform disorders in DSM$\mathrm{V}$ : conceptual and political issues in the debate. Psychosomatics 2006;47:277-281.

22 Cronbach LJ, Meehl PE: Construct validity in psychological tests. Psychol Bull 1955;52: 281-302.

23 Fletcher RH, Fletcher SW, Wagner EH: Clinical Epidemiology. The Essentials, ed 3. Philadelphia, Lippincott, 1996.

24 Hulley SB, Cummings SR, Browner WS, Grady D, Hearst N, Newman TB: Designing Clinical Research. An Epidemiologic Approach, ed 2. Philadelphia, Lippincott, 2001.

25 Spitzer RL, Kroenke K, Linzer M, Hahn SR, Williams JB, deGruy FV, Brody D, Davies M: Health-related quality of life in primary care patients with mental disorders: results from the PRIME-MD 1000 Study. JAMA 1995; 274:1511-1517.

26 Thomassen R, Van Hemert AM, Huyse FJ, van der Mast RC, Hengeveld MW: Somatoform disorders in consultation-liaison psychiatry: a comparison with other mental disorders. Gen Hosp Psychiatry 2003;25:8-13.

27 Smith GR Jr, Monson RA, Ray DC: Patients with multiple unexplained symptoms: their characteristics, functional health, and health care utilization. Arch Intern Med 1986;146: 69-72.

28 Fink P: The use of hospitalizations by persistent somatizing patients. Psychol Med 1992; 22:173-180. 
-29 Kendell R, Jablensky A: Distinguishing between the validity and utility of psychiatric diagnoses. Am J Psychiatry 2003;160:4-12.

30 Jablensky A: Categories, dimensions and prototypes: critical issues for psychiatric classification. Psychopathology 2005;38: 201-205.

31 Widiger TA: A dimensional model of psychopathology. Psychopathology 2005;38: 211-214.

32 Henningsen P, Zipfel S, Herzog W: Management of functional somatic syndromes: approaches and evidence. Lancet, in press.

33 Aaron LA, Buchwald D: A review of the evidence for overlap among unexplained clinical conditions. Ann Intern Med 2001;134: 868-881.

34 Wessely S, Nimnuan C, Sharpe M: Functional somatic syndromes: one or many? Lancet 1999;354:936-939.

- 35 Henningsen P, Jakobsen T, Schiltenwolf M, Weiss MG: Somatization revisited: diagnosis and perceived causes of common mental disorders. J Nerv Ment Dis 2005;193:85-92.

-36 De Gucht V, Maes S: Explaining medically unexplained symptoms: toward a multidimensional, theory-based approach to somatization. J Psychosom Res 2006;60:349-352.

37 Creed F: Can DSM-V facilitate productive research into the somatoform disorders? J Psychosom Res 2006;60:331-334.

38 Rief W, Sharpe M: Somatoform disorders new approaches to classification, conceptualization, and treatment. J Psychosom Res 2004;56:387-390.
39 Janet P: L' automatisme psychologique. Essay de la psycholgie expérimentale sur les formes inférieures de l'activité humaine. Paris, Félix Alcan, 1889.

40 Freud S, Breuer J: Studien über Hysterie (originally published: 1895). Frankfurt, Fischer; 1979.

41 Schur M: Comments on the metapsychology of somatization. Psychoanal Study Child 1955;10:119-164.

42 Lipowski ZJ: Somatization: the concept and its clinical application. Am J Psychiatry 1988;145:1358-1368.

43 Lipowski ZJ: Somatization: the experience and communication of psychological distress as somatic symptoms. Psychother Psychosom 1987;47:160-167.

44 Brown RJ: Psychological mechanisms of medically unexplained symptoms: an integrative conceptual model. Psychol Bull 2004; 130:793-812.

45 De Gucht V, Fischler B: Somatization: a critical review of conceptual and methodological issues. Psychosomatics 2002;43:1-9.

46 Rief W, Barsky AJ: Psychobiological perspectives on somatoform disorders. Psychoneuroendocrinology 2005;30:996-1002.

47 Kirmayer LJ, Taillefer S: Somatoform disorders; in Turner SM, Hersen M (eds): Adult Psychopathology and Diagnosis, ed 3. New York, Wiley, 1997, pp 333-383.

48 Wise TN, Birket-Smith M: The somatoform disorders for DSM-V: the need for changes in process and content. Psychosomatics 2002; 43:437-440.

49 Mayou R, Levenson J, Sharpe M: Somatoform disorders in DSM-V. Psychosomatics 2003;44:449-451.
50 Janca A: Rethinking somatoform disorders. Curr Opin Psychiatry 2005;18:65-71.

51 Kroenke K: Physical symptom disorder: a simpler diagnostic category for somatization-spectrum conditions. J Psychosom Res 2006;60:335-339.

52 Sharpe M, Mayou R, Walker J: Bodily symptoms: new approaches to classification. J Psychosom Res 2006;60:353-356.

53 Gureje O, Simon GE: The natural history of somatization in primary care. Psychol Med 1999;29:669-676.

54 Kroenke K, Swindle R: Cognitive-behavioral therapy for somatization and symptom syndromes: a critical review of controlled clinical trials. Psychother Psychosom 2000;69: 205-215.

55 Hiller W, Fichter MM, Rief W: A controlled treatment study of somatoform disorders including analysis of healthcare utilization and cost-effectiveness. J Psychosom Res 2003;54:369-380.

56 Fallon BA: Pharmacotherapy of somatoform disorders. J Psychosom Res 2004;56:455460.

57 Greco T, Eckert G, Kroenke K: The outcome of physical symptoms with treatment of depression. J Gen Intern Med 2004;19:813818.

58 Müller T, Mannel M, Murck H, Rahlfs VW: Treatment of somatoform disorders with St. John's wort: a randomized, double-blind and placebo-controlled trial. Psychosom Med 2004;66:538-547. 